\title{
Gostava de surpreender o passado no fundo de cada instante: diálogos entre história e ficção em Os Mandarins
}

\section{J'aimais surprendre le passé au fond de chaque instant: dialogue entre l'histoire et la fiction dans Les Mandarins}

Larissa Carolina de Andrade 1

DOI: $10.28998 / 2317-9945.2020 \mathrm{n} 65 \mathrm{p} 57-67$

\begin{abstract}
Resumo
O objetivo deste artigo é refletir sobre a possivel leitura de Os Mandarins, de Simone de Beauvoir, como se romance histórico. Para tanto, a orientação teórica parte de discussões encontradas principalmente em Ricoeur (2010), Mignolo (1993) e Weinhardt (2011; 2015). A noção de tempo bistórico é concebida pela apropriação do tempo pretérito e pelo modo como esse tempo é figurado na instância ficcional, marcando a vivência das personagens e condicionando a ação romanesca. Beauvoir refigura os tempos do passado no presente, e nele entrecruza a possibilidade de uma relação entre a bistória e a ficção. Isto é, Os Mandarins rompe com a premissa de que o discurso que se enquadra na convenção de ficcionalidade tem as relaçoes entre discurso e mundo cortadas; assim como aquele que se enquadra na convenção de veracidade assumiria uma relação de correspondência entre o discurso e o mundo. Os fios do romance são seguramente tramados ao longo de mais de 700 páginas, desenhando cenas de uma França pós-guerra sob o olhar dos intelectuais parisienses. Os acontecimentos e personagens são tão irreais (pertencentes, nesse momento, ao mundo da ficção) quanto verdadeiros (fizeram parte, num outro momento, da realidade empirica). Os fios de tais convenções entrecruzam-se, portanto.
\end{abstract}

Palavras-chaves: Fiç̧ão. História. Romance

\section{Résumé}

L'objectif de cet article est de réfléchir sur la possible lecture de Les Mandarins, de Simone de Beauvoir, comme si roman historique. Pour ça, l'orientation théorique c'est à propos des discussions fait par Ricoeur (2010), Mignolo (1993) et Weinhardt (2011; 2015). La notion de temps historique est concue par l'appropriation du temps passé et par la manière comme ce temps est figuré dans l'instance fictionnelle, en marquant l'expérience des personnages et en conditionnant l'action romanesque. Beawvoir refigure les temps du passé dans le présent, et y croise la possibilité d'une relation entre l'bistoire et la fiction. C'est-à-dire, Les Mandarins rompt avec la prémisse de que le discours qui correspond à la convention de fictionalité coupe les relations entre les discours et le monde; ainsi comme celui qui correspond à la convention de véracité a une relation directe entre le discours et le monde. Les fils du roman sont tissés sur plus de 700 pages, en désignant des scènes d'une France de l'après-guerre sous les yeux d'intellectuels parisiens. Les événements et les personnages sont aussi irréel (appartenant, maintenant, au monde de la fiction) que vrais (ils faisaient partie, dans autre moment, de la réalité empirique). Les fils de telles conventions se croisent donc.

Mots-clés: Fiction. Histoire. Roman

Recebido em: 28/09/2019.

Aceito em: 17/12/2019.

\footnotetext{
${ }^{1}$ Mestranda em Letras na Universidade Federal do Paraná. Graduada em Letras Português/Francês pela Universidade Estadual Paulista Júlio de Mesquita Filho.
} 


\section{Introdução}

Os Mandarins, romance escrito por Simone de Beauvoir, foi publicado pela primeira vez em 1954 e conquistou, nesse mesmo ano, o prêmio Goncourt. A narrativa apresenta a sociedade intelectual parisiense no final da Segunda Guerra Mundial. A Segunda Guerra, enquanto evento histórico, acompanha o desenvolvimento da narrativa do início ao fim. Beauvoir retrata, a partir de um senso crítico particularizante, os caminhos do existencialismo e daqueles que o viveram enquanto filosofia e prática cotidiana. Quando do recebimento do importante prêmio literário, Beauvoir declara: "J'aurais soubaité qu'on prenne ce livre pour ce qu'il est: ni une autobiographie, ni un reportage : une évocation". 'Daqui em diante surge uma inquietação: Os Mandarins, ao não corresponder, segundo a autora, nem como autobiografia - gênero que me parece estar mais próximo da convenção de ficcionalidade, conforme postulado por Mignolo (1993) -, nem como reportagem - que se enquadraria mais fortemente na convenção de veracidade - poderia ser lido como ficção histórica? Se sim, quais são os recursos esteticamente mobilizados? Como se instaura, dentro dessa obra especificamente, o diálogo entre história e ficção? Percorrer esse caminho, penso, é questionar por que a autora, numa tentativa de fuga às classificações, trata sua obra por uma evocação.

A tentativa é de entender como se dá o imbricamento histórico e ficcional na chave dos estudos sobre romance histórico. Uma possível conclusão seja, talvez, de que Os Mandarins não se encontra na esteira dos chamados romances históricos contemporâneos. Ainda assim, creio que o movimento de análise não se torna irrelevante, uma vez que estarei em diálogo com o campo teórico e crítico sobre o romance histórico e observando, de acordo com as solicitações da própria obra enquanto objeto constitutivo de um fazer ficcional, suas possibilidades de leitura. Portanto, o movimento é o de tentar perceber os pontos de aproximação com uma possível leitura de ficção histórica, assim como apontar seus distanciamentos.

À análise.

\section{A ficcionalização de um evento histórico}

Falar de literatura é falar sobre tempo, temporalidade, experiência, realidade, ficção e narrativa. Cada sociedade, e dentro dela cada autor, desenvolve e demonstra uma compreensão de tempo e temporalidade. Nesse sentido, todo trabalho de crítica também apresenta uma teoria sobre a relação entre literatura e história.

As literaturas, sejam elas de cunho mais histórico ou mais ficcional, compartilham o ato de narrar como um aspecto comum, ou seja, é pela (e na) construção verbal que o processo de criação de uma realidade se torna possível; as narrativas históricas e ficcionais, dessa forma, são frutos da imaginação. Como defende Barthes (1988 apud WEINHARDT, 2011, p. 16), se o "imaginário é a linguagem pela qual o enunciante do discurso (entidade puramente linguística) preenche o sujeito da enunciação (entidade puramente psicológica)", a existência de um romance, e dos temas dos quais trata em seu interior, por exemplo, é sobretudo linguística, por isso não consegue situar-se no campo "extra-estrutural" do "real",

\footnotetext{
2 “Eu gostaria que pudéssemos receber esse livro pelo que ele é: nem uma autobiografia, nem uma reportagem: uma evocação" (tradução minha).
} 
visto que a maneira de se conhecer a "realidade" é pelo discurso e pelos modos de preenchimento dos espaços de enunciação. Em Os Mandarins, a Segunda Guerra Mundial, reconhecida como um marco da "História" humana, figura como evento central da narrativa, ou seja, pela fresta dos impactos desse acontecimento é que vemos as personagens em suas vidas cotidianas. No entanto a Segunda Guerra não aparece em forma de documento, e é apresentada dentro de um tempo específico, que situa a narrativa: o tempo do pós-guerra. De uma França econômica, política, cultural e moralmente devastada; de uma sociedade que teme uma possível terceira guerra mundial, mas se sente impotente frente à guerra fria em curso, ou até mesmo incapaz de percebê-la. Ou seja, o espaço-tempo da ambientação é conhecido através da apresentação das próprias personagens, no que concerne aos seus pensamentos, sentimentos, ações... Vejamos o primeiro parágrafo do capítulo I:

Henri lançou um derradeiro olhar para o céu: um cristal escuro. Mil aviões destruindo o silêncio, difícil imaginar. Todavia, as palavras lhe carambolavam na cabeça, como um ruído alegre: ofensiva paralisada, derrota alemã, vou poder partir. Dobrou a esquina no cais. As ruas cheirariam a óleo e a flor de laranjeira, pessoas falariam alto nos terraços iluminados, ele tomaria um café de verdade, ao som dos violões. Seus olhos, suas mãos, sua pele tinham fome. Que prolongado jejum! [...] (BEAUVOIR, 2017, p. 8).

Antes, vale dizer que duas vozes diferentes ocupam o lugar de narrador: de um lado temos um narrador em terceira pessoa que observa através do olhar de Henri; por outro, há uma narradora em primeira pessoa, assumidamente mulher - Anne. Defendo que essas duas vozes criam duas narrativas distintas, que tecem, por sua vez, a teia de um mesmo enredo. A necessidade de realizar essa distinção é porque cabe analisar, também, as primeiras partes da fala de Anne, quando esta assume a voz da narração, ou, dizendo de outra forma, assume a posição de sujeito da enunciação:

Não, não vai ser hoje o dia em que conhecerei minha morte. Nem hoje, nem nunca. Morrerei para os outros, sem jamais me ver morrer. Fechei de novo os olhos, mas sem poder recuperar o sono. Por que a morte se intrometeu outra vez em meus sonhos? Ela ronda, sinto que ronda. Por quê? [...]

Não consigo lembrar. Não éramos muito atentos à nossa própria vida. Só os acontecimentos importavam: o êxodo, o retorno, as sirenes, as bombas, as filas, nossas reuniões, os primeiros números de L'Espoir [...] Fora, havia poças de sangue, o estalejar de balas, o ribombar dos canhões e dos tanques. Havia em todos nós o mesmo silêncio, a mesma fome, a mesma esperança. De manhã acordava-nos a pergunta de sempre: será que a suástica ainda está flutuando no alto do Senado? [...] (BEAUVOIR, 2017, p. 30-31).

Percebe-se que a Segunda Guerra está evidenciada nos dois discursos por construções como "derrota alemã", "as sirenes, as bombas, as filas", "ribombar de canhões e dos tanques", pelo símbolo da suástica, dentre outros elementos. Esse evento é o ponto de partida da narrativa e da própria constituição das personagens, por isso o trato como episódio central do enredo, em torno do qual orbitam variados temas, como liberdade, morte, busca pela identidade, loucura, razão, felicidade, amor. As certezas que as personagens tinham sobre si, sobre suas relações com o outro e com o mundo, foram abaladas pela guerra; porém, enquanto havia necessidade de luta, elas confiavam em seus posicionamentos e ações 
revolucionárias, no entanto, finda a guerra, veem-se perdidas nesse novo tempo do pósguerra.

[...] Mas, de fato, não sabia em que devia crer, nem o que devia fazer. Não sabia nada. Estava ainda atordoado, como se tivesse recebido um forte golpe na cabeça. Evidente que Peltov não havia inventado tudo. Talvez fosse verdade mesmo. Havia campos onde quinze milhões de trabalhadores estavam reduzidos a condições subumanas. Mas, graças a esses campos, o nazismo tinha sido derrotado e um grande país estava sendo construído, no qual residia a única chance de um bilhão de subumanos deteriorando-se de fome na China e na Índia, a única chance de milhões de trabalhadores condenados a um estado desumano [...] As perversões, os abusos da União Soviética, ele os conhecia. Mas esses abusos e perversões não impediam que um dia o socialismo, o autêntico, aquele em que justiça e liberdade se reconciliassem, acabasse por triunfar na URSS e pela URSS. Se hoje essa certeza o abandonasse, então todo o futuro afundaria nas trevas. Em parte alguma seria divisada sequer uma miragem de esperança [...] (BEAUVOIR, 2017, p. 379).

A reconstrução do eu perpassa, dessa maneira, pela necessidade de reconstrução de uma memória histórica, que, aqui, trato tão somente como "memória do passado". Há, no romance, a adoção de uma voz memorialística, que vê no tempo passado, marcado por um evento como a Segunda Guerra Mundial, a garantia de (re)encontro consigo mesmo, com seus mortos, seus sonhos e suas frustrações; esse mesmo passado é o responsável por impelir as personagens na busca por um futuro. Vale dizer que a expressão tempo passado não tem o mesmo significado de tempo histórico. A noção de tempo histórico não implica no tempo de vida do autor ou das personagens, e sim na apropriação que é realizada do tempo pretérito e pelo modo como esse tempo é figurado na instância ficcional, "marcando a vivência das personagens, condicionando a ação romanesca" (WEINHARDT, 2015, p. 130). A recuperação da Segunda Guerra, através da rememoração, vem suprir essa necessidade de, a partir do passado (tempo histórico), se lançar no tempo presente da narrativa (tempo da ficção), onde este guarda uma relação com aquele. A guerra não aparece em forma de documento, ou seja, não se recupera a exatidão de datas, número de ações executadas, quantidade de mortos, líderes políticos etc., nem por isso, por sua vez, o romance deixa de evidenciar o que foi esse momento quando toca nos temas dos movimentos revolucionários, do levante comunista, das correntes de pensamentos filosóficos e políticos efervescentes:

[...] Henri se sentia menos entusiasmado. Evidentemente, tinha mudado desde 1939. Antes era de esquerda, porque a burguesia o enojava, a injustiça o indignava e ele considerava todos os homens como irmãos. Belos sentimentos generosos, que não o comprometiam com coisa alguma [...] A Resistência era uma coisa; a política, outra [...] (BEAUVOIR, 2017, p. 14-15).

- Você com certeza não compreendeu o que Dubreuilh está tramando declarou Scriassine. Fixou em Henri um olhar de reprovação: - Ele organiza uma pretensa esquerda independente, mas que aceita a unidade de ação com os comunistas.

- Sim, eu sei. E daí?

- Bem, ele faz o jogo dos comunistas. Existe muita gente a quem o comunismo apavora e Dubreuilh vai aproximar-se deles.

- Não me venha dizer que você é contrário à unidade de ação - disse Henri. - Seria bonito que a esquerda começasse a dividir-se! 
- Uma esquerda submetida aos comunistas! É uma mistificação - gritou Scriassine. - Se você está decidido a segui-los, inscreva-se no PC. Será mais certo.

- Nada disso. Estamos em desacordo sobre muitos pontos! - protestou Henri.

- Nesse caso, daqui a três meses, os stalinistas denunciarão vocês como socialistas traidores - disse Scriassine, dando de ombros.

- Veremos (BEAUVOIR, 2017, p. 23).

É nesse tempo histórico do pós-guerra, portanto, que se movem figuras fictícias como o escritor, o político, o filósofo, os estudantes, os jovens revolucionários, dentre outras. Porém, Beauvoir não busca pela tipificação dessas personagens, não, ao menos, como referências diretas aos tipos sociais. Se lemos os personagens pelo prisma do conceito de tipos, é preciso entender por um viés Lucáksiano, no qual o "tipo" é visto como um personagem complexo que evidencia a heterogeneidade constitutiva de uma sociedade. É através desse viés que enxergo as personagens de Os mandarins e arrisco uma classificação que torna evidente essa heterogeneidade: os intelectuais (Dubreuilh, Henri, Anne), os escritores, literatos e críticos (Dubreuilh e Henri consubstancialmente, mas também Lenoir, Luc, Lambert), as mulheres da alta sociedade (Claudie, Jeannette, Lucie, Josete), os políticos (Dubreuilh, Samazelle, Scriassine, Trairoux), os jovens revolucionários (Nadine, Vincent, Lambert, Sézenac). É interessante observar que, embora se possam construir categorias, um personagem ocupa mais de uma delas visto sua circulação social, o que aponta mais um traço de sua complexidade. Além disso, como existem dois narradores distintos participando do mesmo enredo, para cada um os personagens com os quais se relacionam encerram-se numa categoria ou outra mais fortemente. Por exemplo, dentro da narrativa de Anne, Robert é um escritor com preocupações literárias e com a própria função dessa literatura na sociedade. $\mathrm{Na}$ narrativa de Henri, Dubreuilh apresenta-se com uma força política, que utiliza seus escritos principalmente com essa finalidade. As leituras não são mutuamente excludentes, mas cada uma apresenta e encerra um olhar específico desse personagem.

A história e a ficção, entrecruzadas, só conseguem concretizar suas intencionalidades quando tomam de empréstimo a intencionalidade uma da outra. Isto é, a ficção se serve da história com o objetivo de refigurar o tempo; a história se serve da ficção com o mesmo intuito. Ricouer (2010) dirá que essa concretização mútua enfatiza a noção de figura. Pergunto-me: a Segunda Guerra, nesse sentido, pode ser lida como uma figura (uma representância) que aproxima o tempo histórico e o ficcional, possibilitando que esses tempos sejam refigurados em Os Mandarins? Falar em refiguração é falar em imaginação. Hayden White, refere Ricoeur, chamará de função "representativa" da imaginação histórica aquela imaginação que, pelo ato de figurar, torna-se visionária, isto é "o passado é o que eu teria visto, aquilo que eu teria sido testemunha ocular se tivesse estado lá, assim como o outro lado das coisas é aquele que eu veria se as olhasse do lugar de onde você as considera. Desse modo, a tropologia torna-se o imaginário da representância" (RICOEUR, 2010, p. 317). Assim, falar de história e/ou eventos históricos é falar de formas de imaginar a representância de um determinado evento. Aqui, é possível enxergar um imbricamento entre história e ficção se considerarmos que a Segunda Guerra, no romance em questão, é tratada como objeto de um certo "imaginário histórico", com isso entendo que o passado datado historicamente passa de reconstruído para refigurado no seio da narrativa de ficção. Logo, o imaginário apresenta traços, dentro do trabalho de refiguração, que são explicitados exclusivamente pela narrativa de ficção, essa, sim, capaz de enriquecer as mediações imaginárias e entrecruzar os campos da ficção e da história pela atividade de refiguração do tempo. 
Os empréstimos que a literatura faz da história e a história da literatura não acontecem somente no plano da configuração, ou seja, no momento da composição, mas concerne também à função representativa da imaginação histórica, o que quer dizer que aprendemos a ver como histórico determinado encadeamento de eventos. Esse entrelaçamento, no entanto, não enfraquece o projeto de representância da própria história, ao contrário, contribuiu para realizá-lo enquanto tal. É o que Ricouer chamará de efeito de ficção; que contribui para a possibilidade de ler o romance Os Mandarins como uma obra de ficção histórica ainda que ele não contenha todos os recursos formais, estilísticos ou de conteúdo exclusivos de um romance histórico. O sentido de leitura que enxergo em $O s$ Mandarins é o que vai da fição para a história e não da história para a ficção, por isso defendo, junto com Ricoeur, a necessidade de se instituir um pacto de leitura entre as vozes narrativas e o leitor implicado. O leitor, quando realiza esse pacto, destina voluntariamente sua confiança, está disposto a conceder para o ficcionista o direito sobre a 'história'. Dessa forma, eu, no lugar de leitora, concedo aos narradores a confiança de me mostrarem (no sentido de refigurar), a partir das vivências individuais de cada personagem, o que foi o período da Segunda Guerra Mundial e do pós-guerra. Na passagem que segue, Henri se questiona sobre essa tripla relação autor-obra-leitor e os contatos entre 'vida real' (dentro do universo ficcional) e 'mundo fictício', instaura-se, assim, a dialética da imaginação:

[...] De quando em quando, um leitor zeloso se supunha obrigado a exalar sua admiração; este tinha ficado afetado pela descrição de uma insônia, aquele por uma frase sobre cemitérios: tratava-se, contudo, de uma passagem insignificante, escrita com indiferença. Guite Ventadour perguntou a Henri, repreensiva, por que ele escolhia como heróis tão tristes senhores. E sorria alternadamente a muitas pessoas infinitamente mais triste. "Como se é severo para com os personagens de um romance", pensava Henri; "não se admite uma fraqueza neles. E como se lê bizarramente! Suponho que, em vez de seguirem os caminhos que lhes são traçados, os leitores, em sua maior parte, percorrem as páginas como cegos. De vez em quando, uma palavra ressoa dentro deles, acordando sabe Deus que lembranças ou nostalgias. Ou então, acreditam ver, em determinada imagem, algum reflexo de si mesmos: detêm-se por um instante, miram-se e continuam, tateando. Seria melhor", concluiu Henri o seu pensamento, "nunca encarar os próprios leitores" [...]" (BEAUVOIR, 2017, p. 335-336).

Os Mandarins também pode ser lido na chave de uma ficção que se coloca como defesa do tremendum horrendum. Pensemos no trecho que segue, escolhido dentre tantas outras passagens passíveis de serem selecionadas:

- Você disse que, eu me calando, serei cúmplice no caso dos campos de concentração - disse ele. - Mas, falando, torno-me cúmplice dos inimigos da URSS, isto é, de todos que querem manter o mundo nas condições em que se acha. Não nego que tais campos sejam uma coisa horrível. Todavia, não se deve esquecer que o horror está em toda parte (BEAUVOIR, 2017, p. 422).

Ricoeur dirá que o horror é o negativo da admiração e vincula-se, por isso, a acontecimentos que é necessário nunca esquecer. O horror constitui, segundo o autor, a motivação ética última da história das vítimas. Assim, as vítimas da Segunda Guerra Mundial,

\footnotetext{
${ }^{3}$ Entendo que a configuração discursiva escolhida por Simone de Beauvoir foi a literária, não a histórica ou antropológica. Isso é o que permite que Os Mandarins seja classificado como romance propriamente, e não como historiografia.
} 
por exemplo, seriam as vítimas da história da memória dos personagens e, por conseguinte, da memória dos leitores. O papel da ficção nessa memória do horrível evidencia a capacidade que o horror tem de se "dirigir a acontecimentos cuja unicidade expressa é importante", ou seja, o horror exerce na consciência histórica uma função específica de individuação. Essa individuação, defende Ricoeur, tem relação com acontecimentos unicamente únicos, uma vez que o horror é responsável por isolar o acontecimento tornando-o "incomparável, incomparavelmente único, unicamente único" (RICOEUR, 2010, p. 321).

A ficção se encontra entre a história, que dissolve o acontecimento na explicação, e uma concepção emocional e subjetivista, pela qual poderia ser tratado um mesmo acontecimento. A ficção, nesse sentido, consegue realçar uma pela outra - a explicação histórica e a individuação dos acontecimentos pelo horror. E aqui percebo que é justamente o movimento empregado em Os Mandarins: uma narrativa de ficção que joga com uma singularidade da explicação autenticamente histórica. Isto é, tanto a explicação histórica quanto a individuação dos acontecimentos pelo horror não são antitéticos. Avalio que as vozes narrativas detêm uma singularidade, é bem verdade, mas nem por isso deixam de falar e dar explicações sobre a história de um evento. A ficção revela-se, portanto, capaz de suscitar uma ilusão de presença, que é controlada por certo distanciamento crítico. Cabe a essa ilusão de presença, que Ricoeur chamará de imaginário de representância, retratar "colocando diante dos olhos". A ficção fornece ao narrador "olhos para ver e para chorar". A vasta ficcionalização do holocausto, por exemplo, comprova essa função. Nesse tipo de ficção, intercala-se uma explicação histórica e um modo de narrar que está em conformidade com as regras da "imputação causal singular". Nesse plano se dá, portanto, a fusão da história com a ficção; especificamente em Os Mandarins essa fusão acontece na dimensão do horrível, quando preserva como "coisas narráveis" a memória do sofrimento, pondo sua ficção a serviço do inesquecível, permitindo que a historiografia se iguale à memória. É preciso que crimes e vítimas não sejam esquecidos, que seus sofrimentos tenham sido narrados, pois "somente a vontade de não esquecer é que pode fazer com que esses crimes não ocorram nunca mais" (RICOEUR, 2010, p. 323). Nesse sentido, e por fim, a obra suscita experiências individuais, por meio de seus personagens, mas não idealiza um passado histórico, estático, parado num tempo diferente daquele do qual (e de onde) se narra.

\section{A historicização na construção da ficção}

Dizer que Beauvoir trata os caminhos do existencialismo e daqueles que o vivenciaram a partir de um senso crítico particularizante é entender como particular justamente a atenção destinada à vida cotidiana. Em Os Mandarins são as personagens em suas vidas medíocres que relatam a experiência da Segunda Guerra Mundial, do pós-guerra e da guerra fria em curso. São suas relações nos âmbitos pessoal, cultural e político que trazem à superfície os "eventos históricos". Esses personagens, no entanto, estão filosoficamente (logo, política e culturalmente) engajados com um modo de ver o mundo: pela lupa do existencialismo.

Henri olhou para Dubreuilh interrogativamente:

- Se o que existe tem sempre razão, só resta cruzar os braços.

- De jeito nenhum. A realidade não é cristalizada. Tem um futuro, tem possibilidades. Apenas, para sobre ela e para pensar nela, é preciso instalarse nela e não perder tempo com sonhos pequenos.

- Você sabe, eu não sonho - Disse Henri.

- Quando a gente diz: "As coisas são más", ou como eu, no ano passado,

"Tudo é mau", é que a gente pensa, calmamente, num bem absoluto. - 
Dubreuilh olhou Henri nos olhos: - A gente não o percebe, mas é preciso uma singular arrogância para colocar os sonhos acima de tudo. Se fôssemos modestos, compreenderíamos que existe, de um lado, a realidade, de outro, nada. Não conheço erro pior do que preferir o vazio ao pleno - acrescentou ele $[. .$.

- Mesmo assim - disse ele -, parece-me antes pessimista essa sua maneira de ver as coisas.

- Ainda aí, não é pessimista senão em relação a ideias que antigamente formulava; ideias muito mais risonhas. A história não é risonha. Mas, como não há meio algum de escapar-lhe, é necessário procurar a melhor maneira de vivê-la: na minha opinião, não é a abstenção (BEAUVOIR, 2017, p. 701).

Com Ricoeur compreendemos que narrar qualquer coisa é narrar como se isso tivesse acontecido. O tempo passado da narrativa funciona como um quase passado temporal. Os acontecimentos contados numa narrativa de ficção são fatos passados para a voz narrativa, disfarçada ficticiamente do autor real. Essa voz que narra fala o que para ela ocorreu. Assim, poderíamos dizer que as crenças filosóficas da autora Beauvoir se confundem, em alguma medida, com a voz narrativa por ela criada. Do mesmo modo que os fatos passados narrados por essa voz se confundem, mas não em sua totalidade, com um passado temporal empírico. Pensando na narrativa de Os Mandarins temos a construção de duas vozes narrativas diferentes e distintas: por um lado, existe um narrador em terceira pessoa que observa e narra a história pelo olhar de Henri; por outro, há uma narradora em primeira pessoa que vive e narra a história a partir de sua individualidade. Essas duas vozes falam de um mesmo tempo, mas constroem narrativas dessemelhantes, ainda assim suas vozes confluem e tecem a teia de um mesmo enredo: a situação de uma sociedade intelectual, no caso a parisiense, no período do pós-guerra. Ler é incluir no pacto entre o leitor e o autor a crença de que os acontecimentos narrados pela voz narrativa pertencem ao passado dessa voz. Portanto, pertence ao passado dessas vozes narrativas os acontecimentos (a Segunda Guerra Mundial, o movimento de Resistência, a Libertação, a Guerra Fria); as menções aos nomes de personalidades históricas (como Stalin, Hitler, Salazar, De Gaulle); a alusão a países (Portugal, Estados Unidos, Nova York, América, China, URSS); os movimentos político-partidários (como a formação do Partido Comunista). Assim como também pertencem a essas vozes as tantas outras referências: a músicos conhecidos (como Django Reinhardt); a escritores (como Thomas Mann); aos jornais que circulavam na época e que ainda hoje se encontram ativos (como Le Figaro e L'Humanitê). Desse modo, Os Mandarins constrói um retrato, sendo uma narrativa de ficção, de como se comportavam, quais lugares frequentavam (aqui encontramos muitos lugares de Paris como Museu Grévin, Palais des Mirages, Montparnasse, Place des Abbesses, entre outros), o que ouviam, comiam e até mesmo como se vestiam mulheres e homens da sociedade intelectual parisiense de meados de 1945. Tudo isso serve, do meu ponto de vista, para construir e refigurar, num outro tempo, que não é tão somente histórico nem tampouco puramente fictício, o próprio passado. E, de certa forma, instaurar um "discurso quase verdadeiro" no presente da narrativa. Os personagens principais não compartilham a existência no mundo empírico, nem tampouco são personalidades conhecidas, mas falam de pessoas, eventos, frequentam lugares, leem livros e escutam músicas que existiram/existem na realidade empírica. Esses personagens vivem os problemas pessoais, políticos e culturais de um tempo passado existente. Será que, ao lançar o olhar por esse viés, posso afirmar que o Os Mandarins constrói, em alguma medida, uma narrativa de cunho histórico? Parece-me que sim. A fim de avançar nessa análise, tomemos o seguinte excerto: 
- Não sou suspeito de gostar de De Gaulle, você o sabe - disse Scriassine. - Mas não pode comparar o que seria uma França gaulista a uma França stalinizada.

- Oh! Você também vai logo gritar: "Viva De Gaulle!"

- Não é culpa minha se as forças anticomunistas se agruparam em torno de um militar - disse Scriassine. - Quando quis reagrupar uma esquerda contra as comunistas, você se negou a isso.

- Se é para ser anticomunista, por que não ser militar? - perguntou Henri. Acrescentou com irritação: - Você fala de uma esquerda! Você dizia: existe um povo americano, existem os sindicatos. E em seus artigos defende Marshall e companhia.

- No momento atual, a divisão do mundo em dois blocos é um fato: somos obrigados a aceitar em bloco a América, ou a URSS (BEAUVOIR, 2017, p. 590).

Os acontecimentos do universo da ficção permanecem irreais se considerado o domínio ao qual pertencem. Esses acontecimentos irreais, que a narrativa de ficção relata, são tratados como fatos históricos para a vOz narrativa que se dirige ao leitor, por isso que se parecem com acontecimentos passados e, desse modo, a ficção se parece com a história. Essa relação, segundo Ricoeur, é circular, "é, por assim dizer, como sendo quase histórica que a ficção dá ao passado essa vivacidade de evocação" (RICOEUR, 2010, p. 325). Nesse sentido, é possível entender o adjetivo que a própria Simone de Beauvoir fornece ao seu livro: trata-se de uma evocação porque dá vivacidade ao passado de maneira quase histórica, mas não absolutamente histórica. No entanto, não se trata aqui de uma função direta, seja histórica ou sociológica, mesclada à função estética, exercida pelo romance. Ricoeur chama a atenção que o quase passado da voz narrativa se distingue totalmente do passado da consciência histórica; a identificação ocorre, no entanto, numa relação de como se passado, que não guarda relação direta e "verdadeira" com o passado histórico. Em suas palavras, "o quase passado da ficção torna-se o detector dos possiveis escondidos no passado efetivo. O que "poderia ter acontecido' [...] abarca tanto as potencialidades do passado 'real' como os possíveis 'irreais' da pura ficção" (RICOEUR, 2010, p. 327). Portanto, o entrecruzamento entre história e ficção na refiguração do tempo se encontra sob uma sobreposição recíproca, com o momento quase histórico da ficção se cruzando com o momento quase fictício da história.

\section{Conclusão}

Como foi possível observar na análise, não me dediquei, neste artigo, a estudar um aspecto específico do romance Os Mandarins (narrador, tempo, espaço, personagens, dentre outros passíveis de análise), mas de tentar enxergar, ao observar a construção do romance como uma obra inteira, as possibilidades de realizar uma leitura que instaurasse um diálogo entre história e ficção. Para tanto, não pude me abster, se é que algum trabalho crítico pode, de lançar sobre o texto uma visão específica sobre literatura, ficção e história, que acredito se relacionarem e produzirem efeitos específicos no texto.

O romance Os Mandarins traz para a ficção várias questões que pertencem ao universo "historiográfico". As vozes narrativas que constroem a obra reconhecem o domínio fictício do qual fazem parte, pois, num movimento metalinguístico, perguntam a si próprias se a literatura deve cumprir esse papel: de contar a "História", uma "história", qual "história"? Enquanto fazem esses questionamentos o romance vai se construindo e a história já está sendo contada. Cabe ao leitor instaurar esse pacto com a própria ficção que se apresenta diante de seus olhos: 
"Verdade que não é fácil ser jovem neste momento", pensou Henri. Decidiu ter uma conversa séria com Lambert, qualquer dia. "E que lhe direi, ao certo?" Começou a tirar a roupa. E disse para si: "Se eu fosse comunista ou cristão, ficaria menos embaraçado. Pode-se procurar impor uma moral universal. Mas o sentido que se dá à própria vida é outra história. Impossível explicar-se em quatro frases: seria preciso levar Lambert a ver o mundo com meus olhos." Henri suspirou. Para isso é que serve a literatura: mostrar o mundo aos outros como a gente vê [...] (BEAUVOIR, 2017, p. 321).

Beauvoir declara que sua obra não é historiográfica, nem autobiográfica, mas evocatória, pois ao "surpreender o passado no fundo de cada instante" (e utilizo-me agora de uma das falas da personagem Anne) Beauvoir refigura os tempos do passado no presente, e nele entrecruza a possibilidade de uma relação entre a história e a ficção, tornando sua obra de fato uma evocação. Isto é, Os Mandarins rompe, desse ponto de vista, com a premissa de que o discurso que se enquadra na convenção de ficcionalidade, recuperando Mignolo (1993), tem as relações entre discurso e mundo cortadas; assim como aquele que se enquadra na convenção de veracidade assumiria uma relação de correspondência entre o discurso e o mundo. Os fios do romance são seguramente tramados ao longo de suas mais de 700 páginas, desenhando cenas de uma França pós-guerra, sob o olhar dos intelectuais parisienses. Os acontecimentos são tão irreais (pertencentes, nesse momento, ao "mundo da ficção") quanto verdadeiros (fizeram parte, num outro momento, do "mundo das coisas", dos acontecimentos); assim como a figura dos intelectuais são tão verdadeiras quanto irreais. Os fios de tais convenções entrecruzam-se, portanto.

A imaginação, aqui, funciona como um conector construído para intermediar o tempo universal e o tempo narrativo, o que possibilita que o tempo histórico seja pensável e maneável. Desse ponto de vista, a ficção não sucede ou concorre com aquela história antes grafada com $\mathrm{H}$ maiúsculo, mas cria diálogos constantes com ela, diálogos que se convertem, para e na literatura, em mecanismos de criação artística, afinal:

[...] Não se detém uma guerra com palavras. Mas a palavra não pretende, sempre, mudar a história; é também uma certa maneira de vivê-la. No silêncio desse escritório, abandonado aos seus íntimos pesadelos, Henri sentia que vivia mal (BEAUVOIR, 2017, p. 722).

Logo, o pano de fundo do romance é a Segunda Guerra e seus desdobramentos. É do passado que se olha o presente; esse mesmo passado, no entanto, não aponta para um possível progresso como emancipação, mas presentifica a catástrofe ocorrida. A história não idealizada é que se corporifica nas narrativas. Concordo com Jameson (2007) quando sugere que essa é uma tentativa de nos acordar para a história, em uma época que seu sentido está atrofiado, num tempo que o passado e o futuro não são mais imperativos. Benjamin (1987), que também desacreditava da ideia de progresso histórico, recupera o Angelus Novus, de Klee, a fim de mostrar sua ideia do despertar. Esse anjo está com a cabeça voltada para o passado, e aquilo que vê o assusta, seu corpo, porém, volta-se para o futuro, ao não conseguir mais fechar as asas e interromper o curso. Seus olhos enxergam uma única catástrofe, onde todos os outros veem uma cadeia de acontecimentos. A história é essa catástrofe única, acumuladora de ruínas. A maneira pela qual se consegue acessá-la é na tentativa de juntar os fragmentos dispersos, apreendidos por quem a experenciou. O romance Os Mandarins apresenta as vozes das experiências de um passado. Considero que a obra não mostra tão somente as existências individuais, nem unicamente o evento histórico, mas garante a intersecção de ambos, organiza, desse modo, um plano mais histórico e outro plano mais 
individual. Para Jameson (2007, p. 192), “o evento precisa trespassar e transfixar de um só golpe o tempo existencial dos indivíduos e seus destinos". Desse modo, concluo como possível que o romance Os Mandarins seja lido como se fosse ficção histórica, justamente pelos diálogos, já aqui demonstrados, instaurados entre história e ficção.

\section{Referências}

BEAUVOIR, S. Os Mandarins. Tradução: Hélio de Souza. Rio de Janeiro: Nova Fronteira, 2017.

BENJAMIN, W. Obras escolhidas I: magia e técnica, arte e política. Trad. Sergio Paulo Rouanet. 3. ed. São Paulo: Brasiliense, 1987.

JAMESON, F. O romance histórico ainda é possível? Novos Estudos, São Paulo, n. 77, p. 185-203, mar. 2007.

MIGNOLO, W. Lógica das diferenças e política das semelhanças: da literatura que parece história ou antropologia e vice-versa. In: MIGNOLO, Walter (Org.) Literatura e história na América Latina. São Paulo: Editora da Universidade de São Paulo, 1993. p. 115-161

RICOEUR, P. Tempo e narrativa. São Paulo: Editora WMF Martins Fontes, 2010. 3 v.

WEINHARDT, M. Romance histórico: das origens escocesas ao Brasil finissecular. In: WEINHARDT, M. (Org.) Ficção histórica: teoria e crítica. Ponta Grossa: Editora UEPG, 2011. p. 12-55.

WEINHARDT, M. A ficção histórica depois de 2010: primeiros apontamentos. Cadernos Literários, v. 23, n. 1, p. 121-135, 2015. 